\title{
Efficacy of entomopathogenic fungi against the stored-grain pests, Sitophilus granarius L. and S. oryzae L. (Coleoptera: Curculionidae)
}

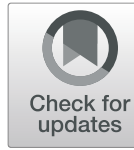

K. Ak

\begin{abstract}
Efficacy of the five native entomopathogenic fungi (EPFs), Beauveria bassiana, Isaria fumosorosea, Lecanicillium muscarium, Metarhizium anisopliae, and Simplicillium lamellicola, against adults of the stored-grain insect pests, Sitophilus granarius and Sitophilus oryzae (Coleoptera: Curculionidae), was evaluated under laboratory conditions at two different

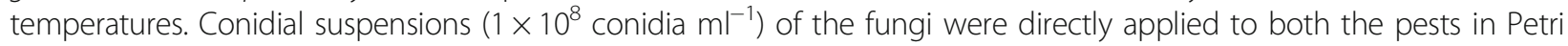
dishes ( $2 \mathrm{ml}$ per dish), using a Potter spray tower. All the dishes were incubated both at 20 and $25^{\circ} \mathrm{C}$ in $16 \mathrm{~h} \mathrm{light} / 8 \mathrm{~h}$ dark and in $75 \pm 5 \%$ relative humidity (RH). Dead individuals were counted daily, following treatments, for 7 days. Lethal time values ( $L T_{50}$ and $\left.L T_{90}\right)$ for EPFs were calculated. The results demonstrated that the mortality rates varied according to both the temperature and the tested EPFs. The highest effect among EPFs at $\left(1 \times 10^{8}\right.$ conidia $\left.\mathrm{ml}^{-1}\right)$ concentration on S. granarius at $20^{\circ} \mathrm{C}$ at the end of day 7 was showed by I. fumosorosea (92.69\%) and M. anisopliae (90.35\%), followed by the other EPFs. Similarly, M. anisopliae and I. fumosorosea were the most effective ones with 90.48 and $84.21 \%$ mortality rates, respectively, at $25^{\circ} \mathrm{C}$. However, while M. anisopliae (85.68\%) showed the highest effect among all the EPFs applied on S. oryzae at $20^{\circ} \mathrm{C}, \mathrm{B}$. bassiana with a mortality rate of $93.66 \%$ was the most effective one at $25^{\circ} \mathrm{C}$. $\mathrm{LT}_{50}$ values for I. fumosorosea and M. anisopliae were 2.75 and 2.88/days, respectively, and $L T_{90}$ values were 4.17 and $4.47 /$ days, respectively, at $20^{\circ} \mathrm{C}$ for $\mathrm{S}$. oryzae. However, $L T_{50}$ values for M. anisopliae on S. granarius in both temperatures were the lowest. This study indicated that M. anisopliae and I. fumosorosea had a significant potential as a biological control agent against S. granarius and S. oryzae. Further studies are necessary to evaluate the efficacy of the isolate on the pests under storage conditions.
\end{abstract}

Keywords: Entomopathogenic fungi, Sitophilus granaries, Sitophilus oryzae, Biological control

\section{Background}

Sitophilus weevils, including Sitophilus oryzae (rice weevil), S. zeamais (maize weevil), and S. granarius (granary weevil) (Coleoptera: Curculionidae), are well-known stored-grain insect pests in Turkey and many other countries in the world (Bağcl et al. 2014). These weevils have a nearly cosmopolitan distribution, occurring throughout all warm and tropical parts of the world (Hong et al. 2018). Generally, because of the storage-grain pests infestation, it has been estimated that during storage, $10-25 \%$ of the grain crops are damaged yearly worldwide. Damages caused by the insects not only contain the direct feeding harm resulting in loss of weight, but they also seriously decrease nutrients, lowering seeds germination rate, reducing quality, and lowering their marketing value due to the mass of waste, webbing, and insect cadavers (Abdel-Raheem et al. 2015).

Stored-grain protection against the pests is currently based on the use of synthetic insecticides and fumigants (Arthur 1996). As a result, these have caused problems including insecticide resistance along with contamination of many food products with chemical residues and

Correspondence: kibarak@yahoo.com

Plant Health Department, Black Sea Agricultural Research Institute, 55300

Tekkeköy, Samsun, Turkey 
consumer demand for pesticide-free grain. Thus, there is a growing interest in using biological control agents against the pests as an alternative (Wakil et al. 2015).

Entomopathogenic fungi (EPFs) are common natural enemies of arthropods worldwide, attracting attention as a potential biological control agent. There are more than 700 species of EPFs (Sandhu et al. 2012; Erper et al. 2016). Fungal entomopathogens such as Beauveria bassiana, B. brongniartii, Isaria farinosa, I. fumosorosea, Lecanicillium spp., and Metarhizium anisopliae play an important role in the regulation of insect populations (Zimmermann 2008; Gurulingappa et al. 2011). Also, since they exist in nature, EPFs have low environmental impact and are generally considered environmentally safe agents with low mammalian toxicity (Rumbos and Athanassiou 2017).

The using of EPFs for the control of the insect pests in stored-grain products is one of the most promising alternative control methods (Moore et al. 2000). Especially, the species $B$. bassiana and $M$. anisopliae have a wide host range and have been tested against most of the major stored-grain pests (Batta 2018; Rumbos and Athanassiou 2017).

Temperature plays a significant role on the effectiveness of EFPs, especially high temperatures affect negatively conidial viability and germination (Rumbos and Athanassiou 2017). For example, B. bassiana was found to be more effective against $R$. dominica, S. oryzae at $26^{\circ} \mathrm{C}$ than at $30^{\circ}$ C (Vassilakos et al., 2006), and S. granarius (Athanassiou and Steenberg 2007) in stored wheat. Similarly, Michalaki et al. (2007) found that Isaria fumosorosea was more effective at $20^{\circ} \mathrm{C}$ than at $25^{\circ} \mathrm{C}$. In another study, I. fumosorosea was effective against Tribolium confusum and Ephestia kuehniella, but its effectiveness was highly dependent on the target species and life stage, exposure interval, and temperature (Michalaki et al. 2007).

The aim of this study was to evaluate the efficacy of five EPFs isolates, belonging to I. fumosorosea, Simplicillium lamellicola, B. bassiana, M. anisopliae, and L. muscarium, against the storage-grain pests, S. granarius and S. oryzae, at two different temperatures under laboratory conditions.

\section{Materials and methods}

\section{Fungi cultures}

Five respect isolates (TR-01, TR-07, TR-78-3, TR-106, and TR-217) of the entomopathogenic fungi (EPFs), I. fumosorosea, Simplicillium lamellicola, B. bassiana, M. anisopliae, and L. muscarium, were used in the present study. They were isolated from different infected hosts in hazelnuts orchards in the Black Sea region of Turkey (Erper et al. 2016; Kushiyev et al. 2018). The single-spore cultures of B. bassiana (TR-217 isolate), I. fumosorosea (TR-78-3 isolate), L. muscarium (TR-07 isolate), M. anisopliae (TR-106 isolate), and S. lamellicola (TR-01 isolate) were stored at $4{ }^{\circ} \mathrm{C}$ on Sabouraud dextrose agar (SDA; Merck Ltd., Darmstadt, Germany) slants and deposited in the fungal culture collection of the Mycology Laboratory at the Ondokuz Mayis University, Faculty of Agriculture's Department of Plant Protection in Samsun, Turkey.

\section{Insect cultures}

Adults of S. granarius and S. oryzae were used. Adult insects were obtained from stock cultures in the Black Sea Agricultural Research Institute (Samsun-Turkey). Insects in cultures were grown at $25 \pm 2{ }^{\circ} \mathrm{C}, 65 \pm 3 \% \mathrm{RH}$ in 16 -h light/8-h dark conditions and fed on sterile wheat grains. Adults from cultures were collected by an oral aspirator and 1-day-old adults were used in the study.

\section{Inoculum of EPF}

The five isolates of EPFs were incubated on potato dextrose agar (PDA; Merck Ltd., Darmstadt, Germany) at 25 $\pm 1{ }^{\circ} \mathrm{C}$ for $10-14$ days. Conidia were harvested by sterile distilled water, containing $0.02 \%$ Tween 20 . Then, conidia suspensions were filtered through four layers of sterile cheesecloth to remove mycelium, and conidia were counted under an Olympus CX-31 compound microscope (Olympus America Inc., Lake Success, NY), using a Neubauer hemocytometer to calibrate a suspension of $1 \times 10^{8}$ conidia $\mathrm{ml}^{-1}$ of each isolate (Erper et al. 2016).

\section{Conidial germination assessment}

The viability of conidia of the five isolates belonging to $B$. bassiana, I. fumosorosea, L. muscarium, M. anisopliae, and S. lamellicola was determined. A conidial suspension $(200 \mu \mathrm{l})$ of each isolate at $\left(1 \times 10^{4}\right.$ conidia $\left.\mathrm{ml}^{-1}\right)$ obtained by dilution was sprayed onto Petri plates (9-cm dia.), containing PDA (Merck Ltd., Darmstadt, Germany). These plates were incubated at $25 \pm 1{ }^{\circ} \mathrm{C}$. After $24 \mathrm{~h}$ of incubation, the percentage of germinated conidia was counted, using an Olympus CX-31 compound microscope at $\times 400$ magnification. Conidia were regarded as germinated, when they produced a germ tube, at least half of the conidial length. The germination ratios for each isolate were calculated after examining a minimum of 200 conidia from each of the three replicate plates (Saruhan et al. 2015).

\section{Experimental design}

Ten S. granarius and S. oryzae adults were released in each Petri plate (9-cm dia.), containing 10 pieces of sterilized wheat grain. Bottoms of plate cups were covered by a filter paper moisturized with sufficiently sterile distilled water. Conidial suspension $\left(1 \times 10^{8}\right.$ conidia $\left.\mathrm{ml}^{-1}\right)$ of each EPF (TR-217, TR-78-3, TR-07, TR-106, and TR-01) was applied to the $S$. granarius and S. oryzae adults ( $2 \mathrm{ml}$ per plate), using a Potter spray tower (Burkard, Rickmansworth, Hertz UK). Control Petri plates were treated by sterile distilled water $(2 \mathrm{ml})$, containing $0.02 \%$ Tween 20 . All the 
plates were loosely covered by a Parafilm to prevent their escape and incubated both at $20 \pm 1$ and at $25 \pm 1{ }^{\circ} \mathrm{C}$ in 16 $\mathrm{h}$ light $/ 8 \mathrm{~h}$ dark and in $75 \pm 5 \% \mathrm{RH}$, using the Memmert incubator (Model ICP 110; Germany). The spray tower was cleaned by $70 \%$ ethanol and sterile distilled water after each application of the fungus suspension.

Dead adults were counted, using a Leica EZ4 stereo dissecting scope at $\times 40-70$ magnification. They were removed daily from the plates and immediately surface disinfected by dipping it in $1 \%$ sodium hypochlorite $(\mathrm{NaOCl})$ for $3 \mathrm{~min}$ and in $70 \%$ ethanol for $3 \mathrm{~min}$. Then, the dead insects (belonging to S. granarius and S. ory$z a e)$ were washed three times in sterile distilled water and placed in $75 \pm 5 \% \mathrm{RH}$, using the Memmert incubator. Mortality rates were confirmed by examining of hyphae on the cadavers under Leica EZ4 stereomicroscope, 10 days after placing the dead insects (Kocaçevik et al. 2016). The bioassay was performed by using a completely randomized experimental design with five replicates. Each replicate consisted of 10 1-day-old adults of the pests and placed in a Petri plate (9- $\mathrm{cm}$ dia.), and the experiment was conducted once (Saruhan et al. 2015).

\section{Statistical analysis}

The mortality rate was observed at 7 days, following each application. Dead individuals were counted under a stereoscopic microscope and the mortality rate was calculated. Data was corrected by Abbott's formula (Abbott 1925). Fifty percent lethal time $\left(\mathrm{LT}_{50}\right)$ and $90 \%$ lethal time $\left(\mathrm{LT}_{90}\right)$ were determined, using the probit analysis by SPSS (ver. 21) program. The effects on mortality rates of the $S$. granarius and $S$. oryzae were analyzed, using the two-way analysis of variance (ANOVA), followed by a comparison of means, using the Tukey HSD test (SPSS) $(P<0.05)$.

\section{Results and discussion}

The efficacy of the five different EPFs, I. fumosorosea, Simplicillium lamellicola, B. bassiana, M. anisopliae, and $L$. muscarium, against adults of storage-grain pests $S$. granarius and $S$. oryzae at two different temperatures $\left(20-25^{\circ} \mathrm{C}\right)$ under laboratory conditions was evaluated.

Among the EFPs, I. fumosorosea (92.69\%) and M. anisopliae $(90.35 \%)$ recorded the highest effects on S. granarius at $20^{\circ} \mathrm{C}$ at the end of day 7 , followed by $B$. bassiana (72.91\%), S. lamellicola (62.02\%), and L. muscarium (33.91\%). The same isolates were tested at $25^{\circ} \mathrm{C}$, where the highest effect, recorded at this temperature, was by M. anisopliae ( $90.48 \%$ ), followed by I. fumosorosea (84.21\%), S. lamellicola (59.26\%), B. bassiana (56.14\%), and $L$. muscarium (22.81\%). The effects of these isolates on $S$. granarius at different temperatures were similar but slightly low at $25^{\circ} \mathrm{C}$ (Figs. 1 and 2). Sheeba et al. (2001) applied B. bassiana against $S$. oryzae and recorded $(86.2 \%)$ the mortality rate in adults after day 25. In another study, Khashaveh et al. (2011) tested the commercial product of B. bassiana against $S$. granarius, Oryzaephilus surinamensis, and Tribolium castaneum at $24 \pm 2{ }^{\circ} \mathrm{C}$ recording 88.33, 78.31, and $64.99 \%$ mortality, respectively. Among these three pests, S. granarius was reported to be the most sensitive.

Among the isolates applied on $S$. oryzae at $20^{\circ} \mathrm{C}, M$. anisopliae showed the highest effect (85.68\%), followed by I. fumosorosea (63.32\%), S. lamellicola (48.06\%), L. muscarium (45.10\%), and B. bassiana (40.74\%). For the same pest at $25^{\circ} \mathrm{C}, \mathrm{B}$. bassiana had the highest effect (93.66\%) at this temperature, followed by M. anisopliae (90.40\%), I. fumosorosea (58.02\%), L. muscarium $(56.86 \%)$, and S. lamellicola (54.74\%). With the rise of temperature, the effect of isolates against $S$. oryzae was increased (Figs. 3 and 4).

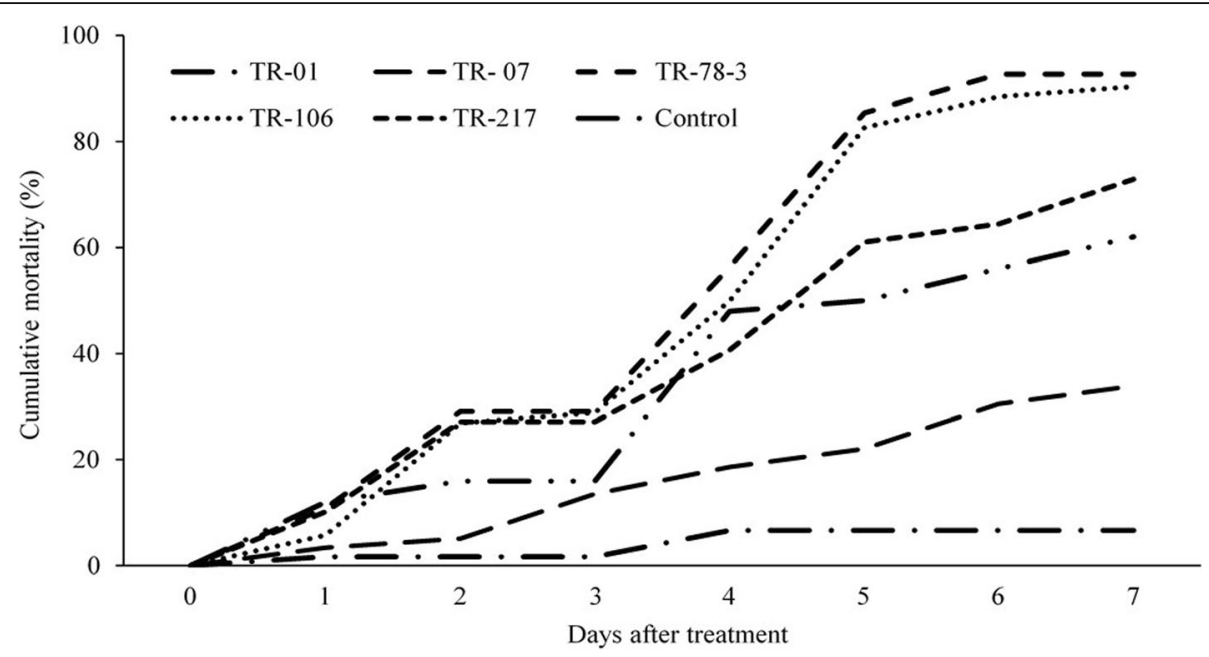

Fig. 1 Mortality rate of Sitophilus oryzae treated with entomopathogenic fungi at $20^{\circ} \mathrm{C}$ 


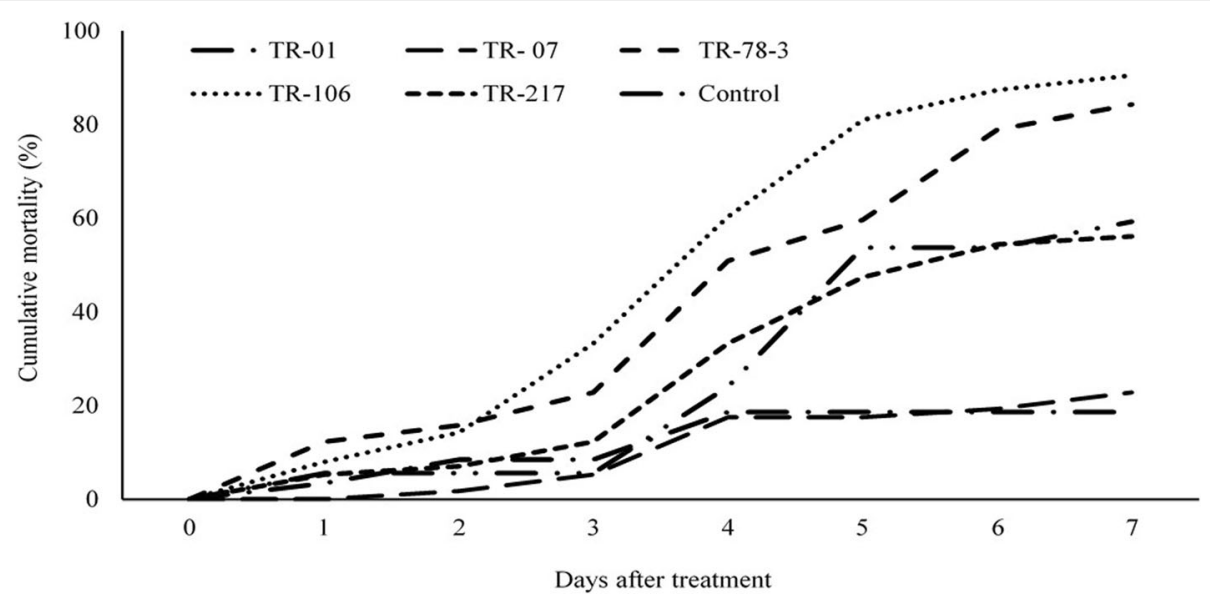

Fig. 2 Mortality rate of Sitophilus oryzae treated with entomopathogenic fungi at $25^{\circ} \mathrm{C}$

Temperature plays a significant role for the effectiveness of EPFs. It is widely accepted that high temperatures affect negatively the conidial viability and germination (Rumbos and Athanassiou 2017). Generally, different fungal species have different temperature requirements. For instance, regarding several strains of $B$. bassiana, the optimum temperature for conidial germination and vegetative growth is around $25^{\circ} \mathrm{C}$ (Rumbos and Athanassiou 2017), while I. fumosorosea was more effective at $20^{\circ} \mathrm{C}$ than at $25^{\circ} \mathrm{C}$ (Michalaki et al. 2007). In the present study, the efficacy of the isolate of I. fumosorosea was the highest $(92.69 \%)$ on S. granarius at $20^{\circ}$ $\mathrm{C}$, while it showed a lower effect $(84.21 \%)$ on the pest at $25^{\circ} \mathrm{C}$. Similarly, the isolate of $\mathrm{B}$. bassiana had the highest effect $(93.66 \%)$ at $25^{\circ} \mathrm{C}$, while it showed the lowest effect $(40.74 \%)$ on the $S$. oryzae at $20^{\circ} \mathrm{C}$. In contrast, $B$. bassiana was found to be more effective (72.91\%) at $20^{\circ}$ $\mathrm{C}$ than $(56.14 \%)$ at $25^{\circ} \mathrm{C}$ against $S$. granarius. Similarly, Tefera and Pringle (2003) found that among different isolates of $B$. bassiana, germination, radial growth, and sporulation of all isolates were retarded at 15 and $35^{\circ} \mathrm{C}$, while the optimum temperature of different isolates of B. bassiana was between 20 and $30{ }^{\circ} \mathrm{C}$ (Tefera and Pringle 2003). Also, the pathogenicity and virulence of $B$. bassiana isolates vary remarkably among the host species and the life stage of the target pest. In the present study, the isolate of B. bassiana was more effective on $S$. granarius than on $S$. oryzae. This finding is also in line with Kassa et al. (2002) who tested 11 isolates of $B$. bassiana against adults of $S$. zeamais and Prostephanus truncatus (larger grain borer) (Coleoptera: Bostrychidae), and as a result, determined that $P$. truncatus was more susceptible to the $B$. bassiana than $S$. zeamais.

The $\mathrm{LT}_{50}$ values of the I. fumosorosea and $M$. anisopliae isolates (2.75 and 2.88 days, respectively), used against $S$. oryzae at $20^{\circ} \mathrm{C}$ at a concentration of $1 \times 10^{8}$ conidia $/ \mathrm{ml}$, showed that they were the most effective ones and they were statistically different from the other

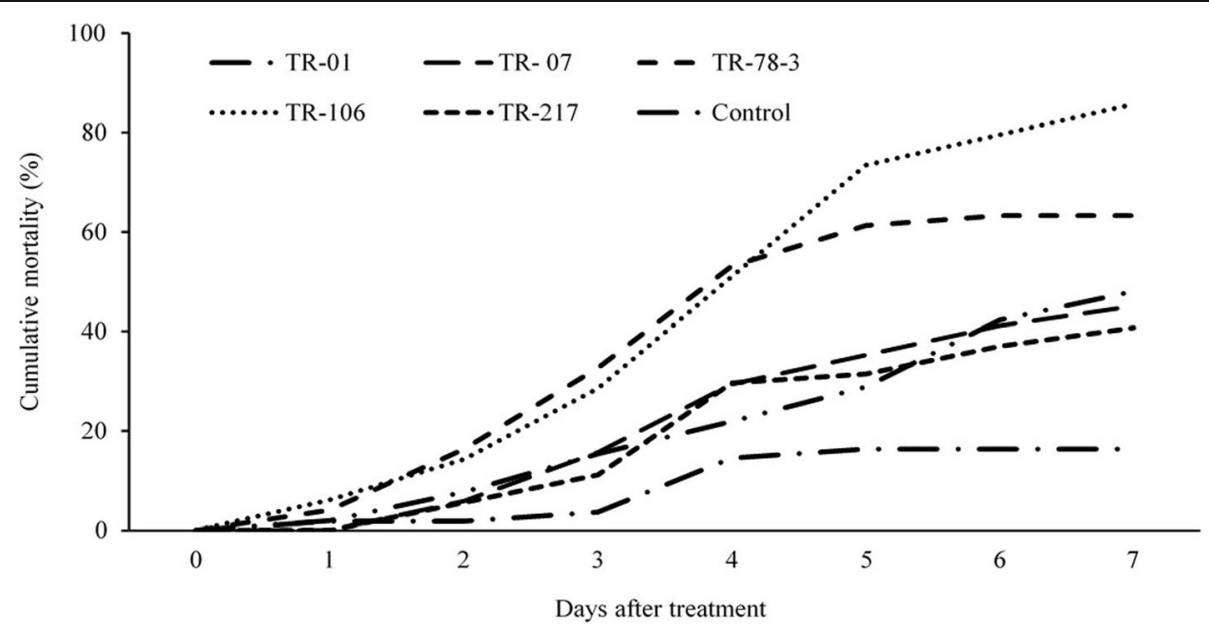

Fig. 3 Mortality rate of Sitophilus granarius treated with entomopathogenic fungi at $20^{\circ} \mathrm{C}$ 


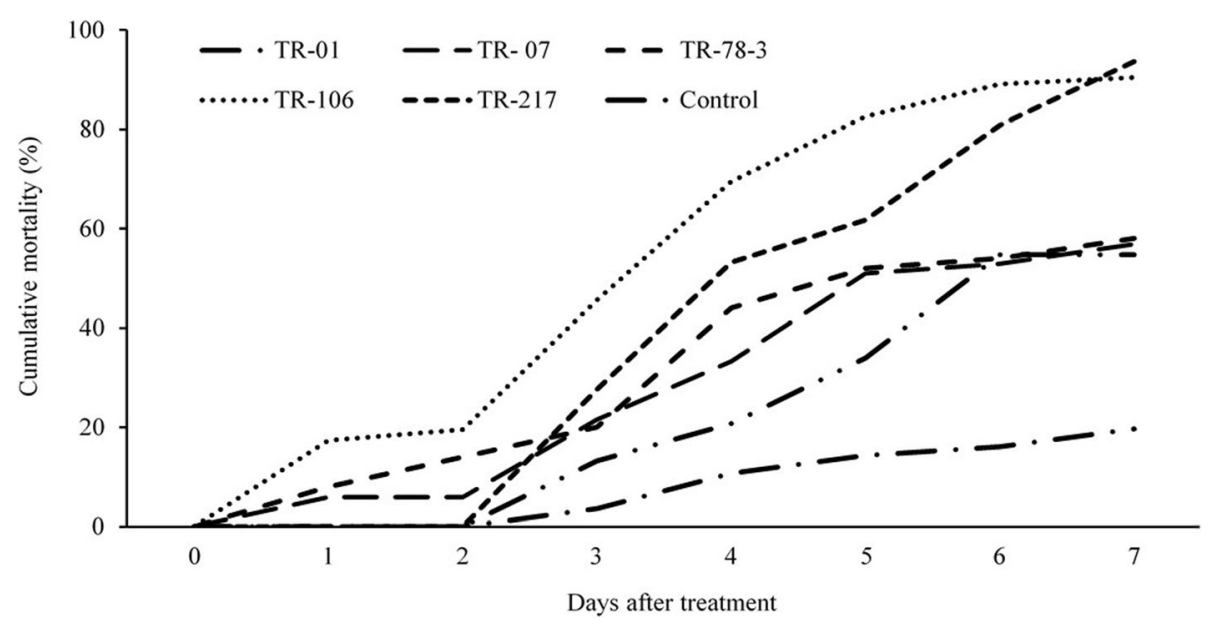

Fig. 4 Mortality rate of Sitophilus granarius treated with entomopathogenic fungi at $25^{\circ} \mathrm{C}$

used isolates. Correspondent $\mathrm{LT}_{50}$ values of $L$. muscarium, S. lamellicola, and B. bassiana at the same concentration and at $20^{\circ} \mathrm{C}$ were $4.78,4.87$, and 5.14 days, respectively. The $\mathrm{LT}_{90}$ values of the EPFs used against $S$. oryzae at $20^{\circ} \mathrm{C}$ had a similar trend to those of $\mathrm{LT}_{50}$. Considering the $\mathrm{LT}_{90}$ values, the most effective EPFs were I. fumosorosea and M. anisopliae (4.17 and 4.47 days), respectively, although the mortality period in adults was lengthen out. These EPFs were determined as L. muscarium, S. lamellicola, B. bassiana (7.67, 7.84, 8.26 days), respectively. The most effective isolate at $\mathrm{LT}_{50}$ at $25^{\circ} \mathrm{C}$ was $M$. anisopliae (2.20 days), followed by $B$. bassiana (3.17 days), I fumosorosea (3.34 days), $L$. muscarium (3.73 days) and S. lamellicola (4.57 days). Similarly, $\mathrm{LT}_{90}$ values of $M$. anisopliae and B. bassiana were 3.82, 3.94 days, respectively, followed by I. fumosorosea with 5.62 days. The lowest effect was recorded for L. muscarium and S. lamellicola (6.42 and 5.92 days, respectively) (Table 1$)$. When the temperature sensitiveness of $\mathrm{LT}_{50}$ values of the used isolates was analyzed, $L$. muscarium and S. lamellicola isolates were found statistically in the same group $(P<0.05) . M$. anisopliae, $I$. fumosorosea, and B. bassiana were different from these two isolates. In a study, the $\mathrm{LT}_{50}$ value was determined as 3.52 days after AAU D (Metarhizium) application against $S$. oryzae at a dose of $1 \times 10^{8}$ conidia $\mathrm{ml}^{-1}$, and $(96.6 \%)$ the mortality rate was determined at the end of day 10. In the same study, the $\mathrm{LT}_{50}$ value of DLCO 141 (Beauveria) was reported as 6.53 days and the mortality rate was $70.0 \%$, and the $\mathrm{LT}_{50}$ value of DLCO 26 (Metarhizium) was 6.21 days and the mortality rate was $60.0 \%$ (Kassaye 2011). In this study, the effect of isolates used against $S$. oryzae was similar to those of the isolates that were used against the same pest species.

According to the results of the isolates of EPFs against $S$. granarius, there was insignificant difference between the results obtained at 20 and $25^{\circ} \mathrm{C}(P<0.05)$ (Table 2). In the present study, $\mathrm{LT}_{50}$ values of the five isolates of EPFs, used against $S$. granarius at $20^{\circ} \mathrm{C}$, were evaluated; S. lamellicola, B. bassiana, I. fumosorosea, and $M$.

Table 1 Lethal time $\left(\mathrm{LT}_{50}\right.$ and $\left.\mathrm{LT} \mathrm{T}_{90}\right)$ for Sitophilus oryzae treated with the tested entomopathogenic fungal isolates at 20 and $25^{\circ} \mathrm{C}$

\begin{tabular}{|c|c|c|c|c|c|c|}
\hline \multirow[t]{3}{*}{ Isolates*** } & \multicolumn{6}{|l|}{ Temperatures } \\
\hline & \multicolumn{3}{|l|}{$20^{\circ} \mathrm{C}$} & \multicolumn{3}{|l|}{$25^{\circ} \mathrm{C}$} \\
\hline & $\mathrm{LT}_{50}$ (95\% confidence limit) & $\mathrm{LT}_{90}(95 \%$ confidence limit) & $x^{2}$ & $\mathrm{LT}_{50}$ (95\% confidence limit) & $\mathrm{LT}_{90}$ (95\% confidence limit) & $x^{2}$ \\
\hline TR-01 & $4.87(4.56-5.23) a^{*} A^{* *}$ & $7.84(7.25-8.63)$ a B & 3.17 & $4.57(4.16-4.98)$ a $A$ & $6.42(5.87-7.27)$ a B & 4.57 \\
\hline TR-07 & $4.78(4.22-5.43)$ a A & $7.67(6.75-9.26)$ a B & 12.79 & $3.73(3.47-3.98)$ b A & $5.96(5.59-6.42)$ a B & 8.17 \\
\hline TR-78-3 & $2.75(2.54-2.97) \mathrm{b} \mathrm{A}$ & $4.17(3.84-4.63) \mathrm{b} \mathrm{B}$ & 1.30 & $3.34(3.08-3.60) \mathrm{b} \mathrm{A}$ & $5.62(5.25-6.08)$ a B & 9.37 \\
\hline TR-106 & $2.88(2.68-3.13) \mathrm{b} \mathrm{A}$ & $4.47(4.09-5.02)$ b B & 3.32 & $2.20(----)$ C A & $3.82(----)$ b B & 11.87 \\
\hline TR-217 & $5.14(4.47-6.04)$ a $A$ & $8.26(7.08-10.59)$ a B & 16.28 & $3.17(3.02-3.32) \mathrm{b} \mathrm{A}$ & $3.94(3.74-4.22)$ b B & 3.67 \\
\hline$F$ & 17.642 & 11.627 & & 34.481 & 24.935 & \\
\hline$P$ & 0.000 & 0.001 & & 0.000 & 0.000 & \\
\hline
\end{tabular}

*The same small letters within columns indicates no significant differences between means

**The same capital letters within rows indicates no significant differences between means

***TR-01 (Simplicillium lamellicola), TR-07 (Lecanicillium muscarium), TR-78-3 (Isaria fumosorosea), TR-106 (Metarhizium anisopliae), and TR-217 (Beauveria bassiana) 
Table 2 Lethal time $\left(L T_{50}\right.$ and $\left.L T_{90}\right)$ for Sitophilus granarius treated with the tested entomopathogenic fungal isolates at 20 and $25^{\circ} \mathrm{C}$

\begin{tabular}{|c|c|c|c|c|c|c|}
\hline \multirow[t]{3}{*}{ Isolates*** } & \multicolumn{6}{|l|}{ Temperatures } \\
\hline & \multicolumn{3}{|l|}{$20^{\circ} \mathrm{C}$} & \multicolumn{3}{|l|}{$25^{\circ} \mathrm{C}$} \\
\hline & $\mathrm{LT}_{50}$ (95\% confidence limit) & $\mathrm{LT}_{90}$ (95\% confidence limit) & $x^{2}$ & $\mathrm{LT}_{50}$ (95\% confidence limit) & $\mathrm{LT}_{90}$ (95\% confidence limit) & $x^{2}$ \\
\hline TR-01 & $3.21(2.45-3.99) a b^{*} A^{* *}$ & $5.50(4.57-7.45)$ a B & 20.64 & $4.01(3.29-4.78)$ b A & $5.90(5.07-7.60)$ b B & 32.61 \\
\hline TR-07 & $6.03(5.54-6.67)$ a A & $10.09(9.02-11.70)$ a B & 4.88 & $7.26(6.13-9.96)$ a A & 11.39 (9.09-17.83) a A & 14.35 \\
\hline TR-78-3 & $2.43(1.27-4.05)$ b A & $4.13(3.07-10.40)$ a $\mathrm{A}$ & 16.92 & $2.78(1.96-3.72)$ b A & $4.52(3.62-7.08)$ b A & 21.05 \\
\hline TR-106 & $2.71(1.93-3.80)$ b A & $4.47(3.51-7.92)$ a A & 10.19 & $2.82(2.52-3.26) \mathrm{b} \mathrm{A}$ & $4.54(3.93-5.60)$ b B & 2.96 \\
\hline TR-217 & $2.95(1.95-5.42)$ a b A & 5.35 (3.88-14.57) a A & 11.03 & $3.91(3.66-4.17) \mathrm{b} \mathrm{A}$ & $6.11(5.74-6.58$ b B & 8.66 \\
\hline$F$ & 4.310 & 1.092 & & 11.514 & 6.234 & \\
\hline$P$ & 0.028 & 0.411 & & 0.001 & 0.009 & \\
\hline
\end{tabular}

*The same small letters within columns indicates no significant differences between means

**The same capital letters within rows indicates no significant differences between means

***TR-01 (Simplicillium lamellicola), TR-07 (Lecanicillium muscarium), TR-78-3 (Isaria fumosorosea), TR-106 (Metarhizium anisopliae), and TR-217 (Beauveria bassiana)

anisopliae were found in the same group, while L. muscarium was in a different group. $\mathrm{LT}_{50}$ values of the isolates, used against $S$. granarius, were 3.21 days $(S$. lamellicola), 2.95 days (B. bassiana), 2.43 days (I. fumosorosea), and 2.71 days (M. anisopliae), while $L$. muscarium was determined as (6.03 days). $\mathrm{LT}_{90}$ values of $\mathrm{EPF}$ applied against $S$. granarius at $20^{\circ} \mathrm{C}$ were found to be at the same group statistically (Table 2 ). The $\mathrm{LT}_{50}$ results of the isolates used against $S$. granarius at $25^{\circ} \mathrm{C}$ showed a similar trend to those obtained at $20^{\circ} \mathrm{C}$. In terms of $\mathrm{LT}_{50}$ values, I. fumosorosea (2.78 days), $M$. anisopliae (2.82 days), B. bassiana (3.91 days), and S. lamellicola (4.01 days) were found to be at the same group statistically, whereas L. muscarium (7.26 days) isolate was found to be low in effect and in a different group statistically. Additionally, in terms of $\mathrm{LT}_{90}$, it was determined that L. muscarium had a low effect (11.39 days) and it was in a different group than other isolates statistically, and $\mathrm{LT}_{90}$ values of the other four isolates ranged 4.52 to 6.11 days and were at the same group statistically (Table 2) $(P<0.05)$.

\section{Conclusion}

In conclusion, the five different EPFs evaluated in this study showed that they were effective against $S$. oryzae and $S$. granarius, and may be considered as alternatives to chemical control. In addition, $M$. anisopliae and $I$. fumosorosea showed about $90 \%$ efficacy against both pests at the end of the day 7 . Thus, they are promising biocontrol agents in terms of practical application according to the results obtained from similar studies. Further studies are necessary to evaluate the efficacy of the isolate on the pests under storage conditions.

\section{Acknowledgments}

I am grateful to Ismail Erper and Islam Saruhan (Ondokuz Mayıs University, Faculty of Agriculture-Turkey) for help in collecting, reproducing, and applying the isolates.
Funding

No funding

\section{Availability of data and materials}

All data are available at the end of the article and the materials used in this work are of high quality and grade.

\section{Authors' contributions}

KA designed the study, supervised the work, wrote the manuscript, and carried out the experiments. The author read and approved the final manuscript.

\section{Ethics approval and consent to participate}

Not applicable

\section{Consent for publication}

Not applicable

\section{Competing interests}

The author declares that there are no competing interests.

\section{Publisher's Note}

Springer Nature remains neutral with regard to jurisdictional claims in published maps and institutional affiliations.

Received: 13 November 2018 Accepted: 15 February 2019

Published online: 05 March 2019

\section{References}

Abbott WS (1925) A method of computing the effectiveness of an insecticide. J Econ Ent; 18:265-267. (http://www.ehabsoft.com/ldpline/onlinecontrol.htm). [Access, 2018]

Abdel-Raheem MA, Ismail IA, Abdel Rahman RS, Farag NA, Abdel Rhman IE (2015) Entomopathogenic fungi, Beauveria bassiana (Bals.) and Metarhizium anisopliae (Metsch.) as biological control agents on some stored product insects. Journal of Entomology and Zoology Studies 3(6):316-320

Arthur FH (1996) Grain protectants: current status and prospects for the future. J Stored Prod Res 32:293-302

Athanassiou CG, Steenberg T (2007) Insecticidal effect of Beauveria bassiana (Balsamo) Vuillemin (Ascomycota: Hypocreales) in combination with three diatomaceous earth formulations against Sitophilus granarius (L.) (Coleoptera: Curculionidae). Biol Control 40:411-416

Bağcı F, Yılmaz A, Sait E (2014) Ankara ili hububat depolarında bulunan zararlı böcek türleri. Bitki Koruma Bülteni 54(1):69-78

Batta YA (2018) Efficacy of two species of entomopathogenic fungi against the stored-grain pest, Sitophilus granarius L. (Curculionidae: Coleoptera), via oral ingestion. Egyptian Journal of Biological Pest Control 28(44):3-8

Erper I, Saruhan I, Akca I, Aksoy HM, Tuncer C (2016) Evaluation of some entomopathogenic fungi for controlling the green shield bug, Palomena 
prasina L. (Heteroptera: Pentatomidae). Egyptian Journal of Biological Pest Control 26(3):573-578

Gurulingappa P, Mcgee P, Sword GA (2011) In vitro and in plants compatibility of insecticides and the endophytic entomopathogen, Lecanicillium lecanii. Mycopathology 172:161-168

Hong KJ, Lee W, Park YJ, Yang JO (2018) First confirmation of the distribution of rice weevil, Sitophilus oryzae, in South Korea. Journal of Asia-Pacific Biodiversity 11:69-75

Kassaye A (2011) Susceptibility of the rice weevil, Sitophilus oryzae (Coleoptera: Curculionidae) to native entomopathogenic fungal isolates. A thesis submitted to the School of Graduate Studies of Addis Ababa University. Addis Ababa University School of Graduate Studies Department of Biology. $51 \mathrm{p}$

Khashaveh A, Ghosta Y, Safaralizadeh MH, Ziaee M (2011) The use of entomopathogenic fungus, Beauveria bassiana (Bals.) Vuill. in assays with storage grain beetles. Journal of Agricultural Science Technology, 13: 35-43

Kocaçevik S, Sevim A, Eroğlu M, Demirbağ Z, Demir I (2016) Virulence and horizontal transmission of Beauveria pseudobassiana S.A. Rehner \& Humber in Ips sexdentatus and Ips typographus (Coleoptera: Curculionidae). Turk J Agric For 40:241-248

Kushiyev R, Tuncer C, Erper I, Ozdemir IO, Saruhan I (2018) Efficacy of native entomopathogenic fungus, Isaria fumosorosea, against bark and ambrosia beetles, Anisandrus dispar Fabricius and Xylosandrus germanus Blandford (Coleoptera: Curculionidae: Scolytinae). Egyptian Journal of Biological Pest Control 28:55 doi.org/10.1186/s41938-018-0062-z

Michalaki MP, Athanassiou CG, Steenberg T, Buchelos CT (2007) Effect of Paecilomyces fumosoroseus (Wise) Brown and Smith (Ascomycota: Hypocreales) alone or in combination with diatomaceous earth against Tribolium confusum Jacquelin du Val (Coleoptera: Tenebrionidae) and Ephestia kuehniella Zeller (Lepidoptera: Pyralidae). Biol Control 40:280-288

Moore D, Lord JC, Smith SM (2000) Pathogens. In: Subramanyam B, Hagstrum DW (eds) Alternatives to pesticides in stored product IPM. Kluwer Academic Publishers, Dordrecht, pp 193-227

Rumbos Cl, Athanassiou CG (2017) Use of entomopathogenic fungi for the control of stored-productinsects: can fungi protect durable commodities? J Pest Sci 90:839-854

Sandhu SS, Sharma AK, Beniwal V, Goel G, Batra P, Kumar A, Jaglan S (2012) Mycobiocontrol of insect pests: factors involved, mechanism, and regulation. Journal of Pathology, Article ID 126819:10

Saruhan I, Erper I, Tuncer C, Akca I (2015) Efficiency of some entomopathogenic fungi as biocontrol agents against Aphis fabae Scopoli (Hemiptera: Aphididae). Pak J Agric Sci 52(2):273-278

Sheeba G, Sundaram S, Nagappan R, Sundaram J, Savarimuthu I (2001) Efficacy of Beauveria bassiana for control of the rice weevil Sitophilus oryzae (L.) (Coleoptera: Curculionidae). Applied Entomology and Zoolgy 36(1):117-120

Tefera T, Pringle K (2003) Germination, radial growth and sporulation of Beauveria bassiana and Metarhizium anisopliae isolates and their virulence to Chilo partellus (Lepidoptera: Pyralidae) at different temperatures. Biocontrol Sci Tech 13:699-704

Vassilakos TN, Athanassiou CG, Kavallieratos NG, Vayias BJ (2006) Influence of temperature on the insecticidal effect of Beauveria bassiana in combination with diatomaceous earth against Rhyzopertha dominica and Sitophilus oryzae on stored wheat. Biol Control 38:270-281

Wakil W, Ghazanfar MU, Yasin M, Kwon YJ (2015) Efficacy of Metarhizium anisopliae combined with diatomaceous earth against Sitophilus oryzae (Coleoptera: Curculionidae) under laboratory conditions. Revista Colombiana de Entomología 41(1):81-86

Zimmermann G (2008) The entomopathogenic fungi Isaria farinosa (formerly Paecilomyces farinosus) and the Isaria fumosorosea species complex (formerly Paecilomyces fumosoroseus): biology, ecology and use in biological control. Biocontrol Sci Tech 18:865-901

\section{Submit your manuscript to a SpringerOpen ${ }^{\circ}$ journal and benefit from:}

- Convenient online submission

- Rigorous peer review

- Open access: articles freely available online

- High visibility within the field

- Retaining the copyright to your article

Submit your next manuscript at $\boldsymbol{\nabla}$ springeropen.com 